\title{
Predictors of Nonoperative Management Failure and Recurrence in Adults with Acute Appendicitis: A Single-Center Retrospective Study
}

Yusuke Wakasa ( $D$ wa1022ka@yahoo.co.jp )

Aomori City Hospital

Yoshikazu Toyoki

Aomori City Hospital

Yuma Kameyama

Aomori City Hospital

Tadashi Odagiri

Aomori City Hospital

Hiroyuki Jin

Aomori City Hospital

Makoto Nakai

Aomori City Hospital

Kazunori Aoki

Aomori City Hospital

Hiroaki Kawashima

Aomori City Hospital

Masaaki Endo

Aomori City Hospital

\section{Research Article}

Keywords: acute appendicitis, nonoperative management, interval appendectomy, failure, recurrence

Posted Date: January 27th, 2022

DOI: https://doi.org/10.21203/rs.3.rs-1256996/v1

License: (c) (1) This work is licensed under a Creative Commons Attribution 4.0 International License.

Read Full License 


\section{Abstract \\ [Purpose]}

Failure and recurrence are concerns in nonoperative management (NOM) for acute appendicitis (AA) and interval appendectomy (IA). The goal of the study was to identify predictors of failure and recurrence in patients with AA who underwent NOM.

\section{[Methods]}

A total of 348 adults with appendicitis were treated in our department from April 2016 to October 2021. Among these patients, 337 who did not undergo emergency surgery were divided into those with failed NOM and unplanned surgery $(n=28)$ and successful NOM $(n=309)$. These groups were compared to identify predictive factors for NOM failure. In the NOM-success group, 195 patients were divided into nonrecurrence $(n=166)$ and recurrence $(n=29)$ groups to identify predictive factors for recurrence of appendicitis.

\section{[Results]}

In multivariate analysis, post-treatment CRP level (odds ratio $(\mathrm{OR})=1.126,95 \%$ confidence interval $(\mathrm{Cl})$ 1.076-1.179, $P=0.000)$ and fecal stones with abscess formation ( $O R=5.530,95 \% \mathrm{Cl}$ 2.081-14.691, $P=0.001$ ) were independently associated with NOM failure. Receiver operating characteristic curve analysis showed an optimum cutoff CRP level of $10.46 \mathrm{mg} / \mathrm{dl}$ for failure appendicitis. The initial CRP level was significantly lower and the \% CRP decrease was significantly higher in the recurrence group than in the non-recurrence group.

\section{[Conclusions]}

These findings suggest that the post-treatment CRP level and fecal stones with abscess formation are predictors of NOM failure, but that recurrence may not be affected by the severity of previous appendicitis.

\section{Introduction}

Acute appendicitis (AA) is a common gastroenterological disease that often requires urgent surgery. However, nonoperative management (NOM) for children with uncomplicated AA appears to be effective based on less morbidity, fewer disability days, and lower costs compared to surgery ${ }^{1,2}$. There are also reports of NOM for uncomplicated AA in adults without use of appendectomy ${ }^{3-5}$. However, failure of NOM is a concern in pediatric and adult patients, with failure rates of $8.5-10 \%$ in patients with 
uncomplicated appendicitis ${ }^{5-7}$, an increased failure risk in patients with an appendicolith ${ }^{6}$, and failure in complicated appendicitis involving abscess formation or perforation. Thus, there is a need to identify patients at high risk for NOM failure to avoid unnecessary observation for such patients.

After NOM for appendicitis, there is a need to consider whether patients should undergo interval appendectomy $(I A)$. One concern with IA is recurrence after NOM, since a recent meta-analysis found a recurrence rate of symptoms within one year of $27.4 \%^{8}$. However, this also indicates that about $70 \%$ of adult patients do not have recurrent appendicitis after NOM. Therefore, careful selection of patients with a low risk of recurrence of $A A$ and requirement for IA may avoid unnecessary surgery ${ }^{9}$. We usually perform NOM for AA cases, except for those with diffuse peritonitis or severe conditions such as septic shock, disseminated intravascular coagulopathy (DIC), or refractory pain control. We then perform IA for cases with appendicitis with fecal stones or abscess formation and for recurrence cases. Herein, we analyzed short-term outcomes of IA and risk factors for NOM failure and recurrence after NOM to evaluate the feasibility of NOM in adult patients with AA.

\section{Materials And Methods}

\section{Patients}

Following approval by our institutional review board, a retrospective analysis was performed for 348 adult patients with AA who were treated at Aomori City Hospital from April 2016 to October 2021. Of these patients, 11 underwent emergency appendectomy and 337 were initially treated with NOM. Of the NOM cases, 309 patients were successfully treated and discharged (NOM-success group), whereas general or abdominal conditions deteriorated in 28 patients and unplanned appendectomy (UA) was performed (NOM-failure group).

Analysis of recurrence was performed in the 300 patients in the NOM-success group, after excluding 6 patients diagnosed with appendix or cecum cancer and 3 patients who wanted to undergo surgery at other institutions. We recommended elective IA for patients in whom a fecal stone or abscess formation was detected in the clinical course and for those with recurrence. A total of 105 patients initially underwent IA. No further treatment was initially performed in 195 patients, of whom 166 had no recurrence (non-recurrence group) and 29 had recurrent appendicitis (recurrence group) and subsequently underwent further NOM. Recurrence was defined as a diagnosis of AA after initial treatment and rehospitalization that required treatment, without considering the period until recurrence.

NOM failed in one patient in the recurrence group and UA was performed. NOM was successful in the other 28 patients with recurrence, of whom 16 underwent subsequent IA and 12 patients refused IA. Thus, in total, 150 patients were treated with appendectomy (excluding emergency appendectomy), including 121 who underwent IA (IA group), and 29 who underwent UA (UA group) (Figure 1).

\section{Diagnosis of appendicitis}


Diagnosis of appendicitis was based on clinical symptoms, such as elevated body temperature, nausea, anorexia, abdominal pain, tenderness in the right lower quadrant, and inflammation in laboratory findings. A contrast CT scan was also routinely performed, and appendicitis was diagnosed if appendiceal dilatation $>5 \mathrm{~mm}$, wall thickening or enhancement, and periappendiceal fat stranding were found. Cases were also divided into uncomplicated and complicated types, with complicated appendicitis defined based on the presence of an appendicolith or abscess formation.

\section{Nonoperative management (NOM) protocol}

All patients were started with withholding of food with intravenous fluid support and administration of cefmetazole or piperacillin/tazobactam, and addition of metronidazole in cases with abscess formation. Clinical condition, including mainly abdominal findings, was evaluated twice daily, and blood tests were usually performed on hospital days 1 and 3 . If the patient did not improve without diffuse peritonitis, treatment was changed by addition or a switch to more broad-spectrum antibiotics, such as meropenem. If conditions worsened despite the change of antibiotics, urgent appendectomy was performed. Patients with an good clinical response to antibiotic therapy, as proved by adequate enteral intake, were discharged. IA was recommended for patients with fecal stones or abscess formation and those with recurrence, who were instructed to visit our hospital after discharge.

\section{Statistical analysis}

Continuous variables are expressed as medians and were compared by Mann-Whitney $\mathrm{U}$ test. Categorical variables were compared by Pearson Chi-square test with a Fisher exact test where appropriate in univariate analysis. Multivariate logistic regression analysis was performed using variables that were significant in univariate analysis. Receiver operating characteristic (ROC) curve analysis was used to analyze the cutoff for each extracted risk factor, and the sensitivity and specificity were calculated. All statistical analyses were performed using SPSS for Windows/Mac ${ }^{\mathrm{TM}}$ ver.25.0 (SPSS Inc., Chicago, IL, USA). Significance was defined at the $5 \%$ level.

\section{Ethics approval and consent to participate}

This study followed the World Medical Association Declaration of Helsinki and strengthening the reporting of observational studies in epidemiology (STROBE) guidelines for cohort studies. All procedures performed in studies involving human participants were in accordance with ethical standards, patient information was reviewed by the Institutional Ethical Review Board of Aomori City Hospital and informed consent exemption was obtained from the IRB of our affiliated institutions (Aomori City Hospital, Approval No. 2021 - 31). All experimental protocols were approved by our institutional committee (Aomori City Hospital, Approval No. 2021 - 31).

\section{Results}

Safety of interval appendectomy (IA) 
The surgical outcomes in the IA and UA groups are shown in Table 1. Laparoscopic approaches were used in 123 patients overall (82.0\%), and significantly more frequently in the IA group compared to the UA group $(97.5 \%(113 / 121)$ vs. $17.2 \%(5 / 29), p=0.000)$. The overall conversion rate to open surgery was $5.7 \%$ (7/123), and was significantly lower in the IA group (4.2\% (5/118) vs. $40 \%(2 / 5), p=0.026)$. The median operation time was 73.0 (range, 26-262) $\mathrm{min}$ and the median blood loss was 2.0 (2-938) $\mathrm{ml}$, and both were significantly lower in the IA group (70.0 vs. $102.0 \mathrm{~min}, p=0.008 ; 2.0$ vs. $40.0 \mathrm{ml}, p=0.000$ ). The overall postoperative complication rate was $10 \%(15 / 150)$, and was also significantly lower in the IA group (3.3\% (4/121) vs. $37.9 \%$ (11/29), $p=0.000)$. Complications of Clavien-Dindo grade ${ }^{10} \geq$ Illa, all of which were residual abscess, were found in 3 patients in all (2.0\%), including 1 in the IA group and 2 in the UA group $(0.8 \%(1 / 121)$ vs. $6.9 \%(2 / 29), p=0.096)$. The median postoperative hospital stay was 4 (1-35) days, and was significantly shorter in the IA group (3 (1-18) vs. 13 (3-35) days, $p=0.000)$.

\section{Risk factors for NOM failure}

The characteristics of the 337 patients ( 186 males, 151 females) are summarized in Table 2 . The NOM failure rate was $8.3 \%$. The median age was 47.0 (16-93) years. The ASA-PS (American Society of Anesthesiologists Physical Status) was 1 in 68 patients (20.2\%), 2 in 230 (68.2\%), and 3 in $39(11.6 \%)$. There was no significant difference in gender, age, or ASA-PS between the NOM-success and NOM-failure groups. In all patients, the median initial white blood cell (WBC) count was $12,695(1,380-24,800) / \mu \mathrm{L}$, post-treatment WBC count was $6,450(1,400-25,000) / \mu \mathrm{L}$, initial C-reactive protein (CRP) level was 3.45 (0.02-48.8) $\mathrm{mg} / \mathrm{dl}$, and post-treatment CRP level was 4.69 (0.04-48.95) $\mathrm{mg} / \mathrm{dl}$. The median \% decreases (post-treatment / initial $\times 100$ ) were $57.1 \%(11.7-623.2 \%)$ for WBC count and $126.3 \%(4.1-71,300.0 \%)$ for CRP.

The NOM-failure group had a significantly higher initial CRP level $(6.87(0.06-34.19) \mathrm{mg} / \mathrm{dl}, \mathrm{p}=0.001)$, post-treatment WBC count $(9,600(3,760-19,870) \mathrm{mg} / \mathrm{dl}, \mathrm{p}=0.000)$, and post-treatment CRP level $(20.39$ (2.31-48.95) $\mathrm{mg} / \mathrm{dl}, \mathrm{p}=0.000)$ compared to the NOM-success group. The $\%$ decreases of WBC count (83.4\% (35.3-285.3\%), $p=0.000)$ and CRP (212.0\% (49.6-12,750.0\%), $p=0.039)$ were significantly higher in the NOM-failure group.

CT imaging showed overall rates of fecal stones of $45.4 \%$ (153/337), abscess formation of $25.8 \%$ (87/337), and fecal stones and abscess formation of $12.5 \%$ (42/337), and each rate was significantly higher in the NOM-failure group $(75.0 \%$ vs $42.7 \%, p=0.001 ; 67.9 \%$ vs $22.0 \%, p=0.000 ; 50.0 \%$ vs $9.1 \%$, $\mathrm{p}=0.000$, respectively). The median appendix diameter was $11(5-30) \mathrm{mm}$, and the appendix was significantly more dilated in the NOM-failure group $(14 \mathrm{~mm}(8-20 \mathrm{~mm}), \mathrm{p}=0.000)$.

In multivariate analysis, the post-treatment CRP level (odds ratio $(O R)=1.126,95 \%$ confidence interval $(\mathrm{Cl})$ 1.076-1.179, $p=0.000)$ and the presence of fecal stones and abscess formation $(\mathrm{OR}=5.530,95 \% \mathrm{Cl} 2.081$ 14.691, $p=0.001$ ) were independently associated with NOM failure (Table 3). ROC curve analysis showed that the optimum cut-off CRP level for NOM failure was $10.46 \mathrm{mg} / \mathrm{dl}$, with $74.1 \%$ sensitivity, $74.0 \%$ specificity, and AUC 0.848 (95\% Cl 0.781-0.916, P=0.000; Figure 2). 


\section{Malignant lesions}

Appendiceal tumors, including low-grade appendiceal neoplasm (LAMN), and colon cancers (cecum and ascending colon) were identified in $2.6 \%$ (9/348) of cases. Of the 309 patients in the NOM-success group, $6(1.9 \%)$ were diagnosed with malignancy after NOM and then underwent ileocecal resection or right hemicolectomy for cancer. In three patients, a malignant lesion was detected pathologically after IA. Two LAMN cases were kept under observation without additional surgery. One patient was diagnosed with appendix cancer after appendectomy and underwent subsequent ileocecal resection.

\section{Risk factors for recurrence}

The recurrence rate was $14.9 \%$ and the median age in recurrence cases was 45.0 (range 16-93) years in the patients in the recurrence and non-recurrence groups (Table 4). There was no significant difference in gender or age between these groups. In these patients, the median initial WBC count was $12,710(1,380$ $24,800) / \mu \mathrm{L}$, post-treatment WBC count was $6,110(1,400-25,000) / \mu \mathrm{L}$, initial CRP level was $3.02(0.02-$ 42.06) $\mathrm{mg} / \mathrm{dl}$, and post-treatment CRP level was $3.37(0.04-31.05) \mathrm{mg} / \mathrm{dl}$. The median \% decreases of WBC count and CRP were $52.6 \%(11.7-623.2 \%)$ and $113.8 \%(4.1-43,680.0 \%)$, respectively. The initial CRP level in the recurrence group $(0.95(0.02-22.62) \mathrm{mg} / \mathrm{dl}, \mathrm{p}=0.001)$ was significantly lower and the \% decrease of CRP $(342.5 \%(25.0-16,745.0 \%), p=0.039)$ was significantly higher than those in the nonrecurrence group. No other parameters differed significantly between the two groups, including the presence of fecal stones, abscess formation, fecal stones or abscess formation, fecal stones and abscess formation, and appendix diameter on CT.

\section{Discussion}

This study investigated the feasibility of NOM for uncomplicated and complicated appendicitis, and the outcomes of IA for high-risk patients. The results showed differences between the IA and UA groups, NOM-success and NOM-failure groups, and recurrence and non-recurrence groups, with three main results. First, the short-term surgical outcomes (operation time, blood loss, complication rate, and postoperative hospital stay) were significantly better in the IA group than in the UA group. Second, posttreatment CRP level, and fecal stones and abscess formation were independent risk factors for NOM failure. Finally, the initial CRP level was significantly lower and the \% decrease in CRP was significantly higher in the recurrence group than in the non-recurrence group.

The feasibility of NOM and subsequent IA remains controversial in terms of morbidity, efficacy, recurrence, and cost. In 2021, a Japanese nationwide study showed that emergency surgery for complicated AA places the patient at relatively higher risk, and that the risk associated with elective appendectomy is significantly lower than that for other methods ${ }^{11}$. A systematic review and metaanalysis showed that immediate surgery is associated with higher morbidity than nonsurgical treatment ${ }^{12}$, and a meta-analysis suggested that, for both uncomplicated and complicated adult AA, NOM with antibiotics was associated with significantly fewer complications and a shorter hospital stay ${ }^{13}$. 
Thus, the benefits of NOM and IA seem to be safe surgery with a lower complication rate, as also seen in our results.

There are also reports that indicate concerns with NOM, including one of the above studies showing lower efficacy and higher relapse with NOM compared to appendectomy ${ }^{13}$. An open-label randomized controlled trial in patients with AA in 2007 demonstrated that amoxicillin plus clavulanic acid was noninferior to emergency appendectomy based on rates of 30-day postintervention peritonitis, unplanned appendectomy, and recurrence ${ }^{14}$. A retrospective study of 1081 patients who underwent appendectomy for AA in 2006 showed that prompt appendectomy is necessary based on the risk of developing advanced pathology, and that postoperative complications increase with time ${ }^{15}$. However, these two studies were performed more than ten years ago and modern conservative treatment strategies including new antibiotics may be more effective.

One advantage of NOM is the potential to explore other possible malignancies after NOM. We routinely perform total colonoscopy after NOM for patients $>40$ years old and we have detected appendiceal tumors or colon cancers in 1.9\% (6/309) of successful NOM cases, with 2.5\% (3/121) diagnosed incidentally after IA. A retrospective review of IA for complicated appendicitis in 402 patients found a $9 \%$ rate for appendiceal neoplasms, with this rate rising to $11 \%$ in patients $\geq 30$ years old and $16 \%$ in patients $\geq 50$ years old ${ }^{16}$. Other reports have shown rates of $10-29 \%{ }^{17-21}$, but the neoplasm rate in patients with complicated appendicitis is thought to be higher ${ }^{19,22,23}$. Therefore, complicated appendicitis, such as that with abscess or mass formation, may be better treated as conservatively as possible from an oncological perspective. NOM and subsequent total colonoscopy are helpful for cancer surgery with complete lymph node dissection for possible appendix or colon cancer.

Regarding NOM for appendicitis, including complicated appendicitis, the two main concerns are failure and recurrence. A randomized controlled study suggested that fever at initial presentation, high presenting serum CRP, and an intraluminal fecalith were risk factors for NOM failure ${ }^{14}$. Another retrospective study showed that the combination of elevated CRP and a fecalith predicted failure of antibiotic therapy in 224 patients who received initial antibiotic therapy ${ }^{24}$. From a radiological perspective, incarceration of an appendicolith and periappendiceal fluid on CT images were suggested as predictive factors for failure of NOM in a retrospective study ${ }^{25}$. In our study, the post-treatment CRP level and abscess formation with a fecalith were identified as independent risk factors for failure of NOM; in particular, the combination of the presence of a fecalith and abscess formation resulted in an extremely high odds ratio for NOM failure.

The recurrence rate of AA has been reported as $14-35 \% 8,14,26,27$ and recurrence risk factors have been identified in several studies. In 2000, a retrospective study in 60 patients with appendicitis suggested an appendix diameter of $>8 \mathrm{~mm}$ measured by ultrasonography was a risk for recurrence ${ }^{28}$. Recently, a retrospective study in 12,235 patients who underwent NOM for appendicitis found that recurrence was independently associated with young age, male sex, percutaneous abscess drainage, and medical center 
admission in multivariate analysis ${ }^{29}$. An initial CRP level $>10.3 \mathrm{mg} / \mathrm{dl}$ was found to be an independent risk factor for recurrence in children with appendicitis with appendiceal masses in a retrospective study in $2017^{30}$. However, our results suggested that the initial CRP level in the recurrence group was significantly lower than that in the non-recurrence group, and that the \% CRP decrease was higher in the recurrence group.

Good surgical outcomes were obtained in patients who underwent IA. This may be due to stable general conditions and vital signs and a low level of inflammation in the IA group. In contrast, in the UA group, hyperbacteremia due to severe appendicitis leading to possible abscess formation or perforation or even peritonitis may have made surgery challenging both intra- and postoperatively. Emergency appendectomy is technically demanding due to distorted anatomy, bowel adhesive loops, and difficulty closing the appendiceal stump because of inflamed tissues ${ }^{31}$. Under such conditions, early laparoscopic appendectomy for AA may be converted to open appendectomy, ileocecal resection, or right hemicolectomy ${ }^{32}$, as found in this study. There may also be complications postoperatively, including infection and organ failure. Emergency surgery should be avoided when possible because of these intraand postoperative difficulties, but conservative treatment also has a risk for mortality.

We found that that the post-treatment CRP level and a combination of fecal stones and abscess formation were associated with NOM failure. CRP is broadly known as a marker that indicates an inflammatory response, and the post-treatment CRP level reflects overall inflammation severity and response to antibiotics. The \% CRP decrease was not a significant factor in multivariate analysis, which may be due to an insufficient effect of antibiotics due to severe inflammation or a result of raising the CRP level belatedly. The presence of abscess formation may also reflect the intensity of inflammation, and there is a need to consider the relationship between fecal stones and inflammation severity, and the location and size of the stone. As mentioned above, incarceration of fecal stones has been suggested to be an independent risk factor for NOM failure ${ }^{25}$ and such incarceration may exacerbate inflammation.

This study showed that the initial CRP level was significantly lower and the \% CRP decrease was significantly higher in the recurrence group than in the non-recurrence group. These results are challenging to interpret because the recurrence rate has been found to increase with more severe inflammation in initial appendicitis in other reports ${ }^{29,30}$. Our results suggest that the severity of initial appendicitis may not be related to recurrence. However, the greater \% CRP decrease might suggest that patients with recurrence are more vulnerable to infection, including appendicitis. Other factors that may be associated with recurrence include microbiota ${ }^{33}$, daily bowel movement ${ }^{34}$, and morphological characteristics of the appendix ${ }^{35}$.

This study has several limitations, including the small number of patients and the retrospective, nonrandomized design without a control group. Also, the definition of complicated appendicitis has not been established and target cases differ among studies, which makes it difficult to compare the present results with those from previous studies. 
In conclusion, the post-treatment CRP level and fecal stones with abscess formation may be predictors of NOM failure. However, recurrence of appendicitis does not seem to be affected by the severity of previous appendicitis, and prediction of recurrence is difficult based on inflammation severity.

\section{Abbreviations}

AA

acute appendicitis

IA

interval appendectomy

NOM

non-operative management

UA

unplanned appendectomy

\section{Declarations}

\section{Data availability}

The datasets used and/or analysed during the current study available from the corresponding author on reasonable request.

Grant Support: Funding was from institutional sources only

Disclosures: There are no potential conflicts of interest relevant to this article

\section{Author Contributions:}

Study concept and design; Yusuke Wakasa and Yoshikazu Toyoki conceived the idea and developed the theory.

Acquisition of data; Yusuke Wakasa, Yuma Kameyama, and Tadashi Odagiri collected the patients' data.

Data analysis and interpretation: Yusuke Wakasa, Hiroyuki Jin, Makoto Nakai, and Kazunori Aoki analyzed and interpreted the data.

Drafting of the manuscripts; Yusuke Wakasa created the draft manuscript.

Critical revision of the manuscript for important intellectual content; Hiroaki Kawashima and Yoshikazu Toyoki discussed the results and contributed to the final version.

Statistical analysis; Yusuke Wakasa performed the analytic calculations.

Study supervision; Yoshikazu Toyoki and Masaaki Endo supervised the study. 


\section{References}

1. Georgiou R, Eaton S, Stanton MP, et al. Efficacy and safety of nonoperative treatment for acute appendicitis: a meta-analysis. Pediatrics 2017;139:e20163003.

2. Minneci PC, Mahida JB, Lodwick DL, et al. Effectiveness of patient choice in nonoperative vs surgical management of pediatric uncomplicated acute appendicitis. JAMA Surg 2016;151:408.

3. Sallinen V, Akl EA, You JJ, et al. Meta-analysis of antibiotics versus appendicectomy for nonperforated acute appendicitis. Br J Surg 2016;103:656-667.

4. Huston JM, Kao LS, Chang PK, et al. Antibiotics vs. appendectomy for acute uncomplicated appendicitis in adults: review of the evidence and future directions. Surg Infect 2017;18:527-535.

5. Podda M, Gerardi C, Cillara N, et al. Antibiotic treatment and appendectomy for uncomplicated acute appendicitis in adults and children: a systematic review and meta-analysis. Ann Surg 2019;270:1028-1040.

6. Huang L, Yin Y, Yang L, et al. Comparison of antibiotic therapy and appendectomy for acute uncomplicated appendicitis in children. JAMA Pediatr 2017;171:426.

7. Becker P, Fichtner-Feigl S, Schilling D. Clinical management of appendicitis. Visceral Med 2018;34:453-458.

8. Harnoss JC, Zelienka I, Probst P, et al. Antibiotics versus surgical therapy for uncomplicated appendicitis: systematic review and meta-analysis of controlled trials (PROSPERO 2015: CRD42015016882). Ann Surg 2017;265:889-900.

9. Kasagi Y, Natsugoe K, Aoyagi T, et al. Validating the efficacy of interval appendectomy for acute appendicitis: representative three cases with different etiologies. Surg Case Rep 2020;6:207.

10. Dindo D, Demartines N, Clavien PA. Classification of surgical complications: a new proposal with evaluation in a cohort of 6336 patients and results of a survey. Ann Surg 2004;240:205-213.

11. Yamada $T$, Endo $H$, Hasegawa $H$, et al. Risk of emergency surgery for complicated appendicitis: Japanese nationwide study. Ann Gastroenterol Surg 2021;5:236-242.

12. Andersson RE, Petzold MG. Nonsurgical treatment of appendiceal abscess or phlegmon: a systematic review and meta-analysis. Ann Surg 2007;246:741-748.

13. Yang Z, Sun F, Ai S, et al. Meta-analysis of studies comparing conservative treatment with antibiotics and appendectomy for acute appendicitis in the adult. BMC Surg 2019;19:110.

14. Vons C, Barry C, Maitre S, et al. Amoxicillin plus clavulanic acid versus appendicectomy for treatment of acute uncomplicated appendicitis: an open-label, non-inferiority, randomised controlled trial. Lancet 2011;377:1573-1579.

15. Ditillo MF, Dziura JD, Rabinovici R. Is it safe to delay appendectomy in adults with acute appendicitis? Ann Surg 2006;244:656-660.

16. Hayes D, Reiter S, Hagen E, et al. Is interval appendectomy really needed? A closer look at neoplasm rates in adult patients undergoing interval appendectomy after complicated appendicitis. Surgical Endosc 2021;35:3855-3860. 
17. Mällinen J, Rautio T, Grönroos J, et al. Risk of appendiceal neoplasm in periappendicular abscess in patients treated with interval appendectomy vs follow-up with magnetic resonance imaging. JAMA Surg 2019;154:200.

18. Wright GP, Mater ME, Carroll JT, et al. Is there truly an oncologic indication for interval appendectomy? Am J Surg 2015;209:442-446.

19. Furman MJ, Cahan M, Cohen P, et al. Increased risk of mucinous neoplasm of the appendix in adults undergoing interval appendectomy. JAMA Surg 2013;148:703-706.

20. Deelder JD, Richir MC, Schoorl T, et al. How to treat an appendiceal inflammatory mass: operatively or nonoperatively? J Gastrointest Surg 2014;18:641-645.

21. Carpenter SG, Chapital AB, Merritt MV, et al. Increased risk of neoplasm in appendicitis treated with interval appendectomy: single-institution experience and literature review. Am Surg 2012;78:339343.

22. Lee WS, Choi ST, Lee JN, et al. A retrospective clinicopathological analysis of appendiceal tumors from 3,744 appendectomies: a single-institution study. Int J Colorect Dis 2011;26:617-621.

23. Mällinen J, Rautio T, Grönroos J, et al. Risk of appendiceal neoplasm in periappendicular abscess in patients treated with interval appendectomy vs follow-up with magnetic resonance imaging: 1-year outcomes of the peri-appendicitis acuta randomized clinical trial. JAMA Surg 2019;154:200-207.

24. Shindoh J, Niwa H, Kawai K, et al. Predictive factors for negative outcomes in initial nonoperative management of suspected appendicitis. J Gastrointest Surg 2010;14:309-314.

25. Kohga A, Kawabe A, Yajima K, et al. Does the presence of an appendicolith or abscess predict failure of nonoperative management of patients with acute appendicitis? Emerg Radiol 2021;28:977-983.

26. Eriksson S, Granström L. Randomized controlled trial of appendicectomy versus antibiotic therapy for acute appendicitis. Br J Surg 1995;82:166-169.

27. Hansson J, Körner U, Khorram-Manesh A, et al. Randomized clinical trial of antibiotic therapy versus appendicectomy as primary treatment of acute appendicitis in unselected patients. Br J Surg 2009;96:473-481.

28. Cobben LP, de Van Otterloo AM, Puylaert JB. Spontaneously resolving appendicitis: frequency and natural history in 60 patients. Radiology 2000;215:349-352.

29. Liang TJ, Liu SI, Tsai CY, et al. Analysis of recurrence management in patients who underwent nonsurgical treatment for acute appendicitis. Medicine (Baltimore) 2016;95:e3159.

30. Chang YJ, Chao HC, Chen $\mathrm{CL}$, et al. C-reactive protein may predict the recurrence of appendicitis in children formerly with appendiceal mass after successful nonoperative treatment. Pediatr Neonatol 2017;58:350-354.

31. Ahmed I, Deakin D, Parsons S. Appendix mass: do we know how to treat it? Ann Royal Coll Surg Engl 2005;87:191-195.

32. Oliak D, Yamini D, Udani VM, et al. Initial nonoperative management for periappendiceal abscess. Dis Colon Rectum 2001;44:936-941. 
33. Vanhatalo S, Munukka E, Sippola S, et al. Prospective multicentre cohort trial on acute appendicitis and microbiota, aetiology and effects of antimicrobial treatment: study protocol for the MAPPAC (Microbiology APPendicitis ACuta) trial. BMJ Open 2019;9:e031137.

34. Raahave D. Faecal retention: a common cause in functional bowel disorders, appendicitis and haemorrhoids with medical and surgical therapy. Dan Med J 2015;62:B5031.

35. Delić J, Savković A, Isaković E. [Variations in the position and point of origin of the vermiform appendix]. Med Arh 2002;56:5-8.

\section{Tables}

Table 1. Surgical factors in the interval appendectomy (IA) and unplanned appendectomy (UA) groups

\begin{tabular}{lllll} 
Variable & Total $(\mathrm{n}=150)$ & $\mathrm{IA}(\mathrm{n}=121)$ & $\mathrm{UA}(\mathrm{n}=29)$ & $\mathrm{p}$ value \\
\hline Approach & & & & \\
\hline Laparoscopic & $123(82.0 \%)$ & $118(97.5 \%)$ & $5(17.2 \%)$ & $\mathbf{0 . 0 0 0}$ \\
\hline Open & $27(18.0 \%)$ & $3(2.5 \%)$ & $24(82.8 \%)$ & \\
\hline Conversion rate $(\%)$ & $5.7(7 / 123)$ & $4.2(5 / 118)$ & $40.0(2 / 5)$ & $\mathbf{0 . 0 2 6}$ \\
\hline Operation time (min) & $73.0(26-262)$ & $70.0(26-262)$ & $102.0(42-216)$ & $\mathbf{0 . 0 0 8}$ \\
\hline Blood loss (ml) & $2.0(2-938)$ & $2.0(2-188)$ & $40.0(2-938)$ & $\mathbf{0 . 0 0 0}$ \\
\hline Complication rate (\%) & $10.0(15 / 150)$ & $3.3(4 / 121)$ & $37.9(11 / 29)$ & $\mathbf{0 . 0 0 0}$ \\
\hline$>$ C-D Grade IIla & $2.0(3 / 150)$ & $0.8(1 / 121)$ & $6.9(2 / 29)$ & 0.096 \\
\hline Postoperative hospital stay (days) & $4(1-35)$ & $3(1-18)$ & $13(3-35)$ & $\mathbf{0 . 0 0 0}$
\end{tabular}

IA: Interval appendectomy

UA: Unplanned appendectomy

Table 2. Patient characteristics, laboratory values, and imaging results in the NOM-success and NOMfailure groups 
Variable

Total $(n=337) \quad$ NOM-success

$(n=309)$

NOM-failure

$(n=28)$

$\mathrm{p}$

value

Gender

Male

$186(55.2 \%)$

$170(55.0 \%)$

$16(57.1 \%)$

0.828

Female

$151(44.8 \%)$

$139(45.0 \%)$

$12(42.9 \%)$

Age (years), median (range)

$47.0(16-93)$

$47.0(16-93)$

$48.0(19-89)$

0.877

ASA-PS (1 / 2 / 3)

\begin{tabular}{|c|c|c|c|c|}
\hline 1 & $68(20.2 \%)$ & $63(20.4 \%)$ & $5(17.9 \%)$ & 0.270 \\
\hline 2 & $230(68.2 \%)$ & $212(68.6 \%)$ & $18(64.3 \%)$ & \\
\hline 3 & $39(11.6 \%)$ & $34(11.0 \%)$ & $5(17.9 \%)$ & \\
\hline $\begin{array}{l}\text { Initial WBC count }\left(/ \mathrm{mm}^{3}\right) \text {, median } \\
\text { (range) }\end{array}$ & $\begin{array}{l}12,695(1,380- \\
24,800)\end{array}$ & $\begin{array}{l}12,725(1,380- \\
24,800)\end{array}$ & $\begin{array}{l}11,685(4,440- \\
22,940)\end{array}$ & 0.696 \\
\hline $\begin{array}{l}\text { Post-treatment WBC count }\left(/ \mathrm{mm}^{3}\right) \text {, } \\
\text { median (range) }\end{array}$ & $\begin{array}{l}6,450(1,400- \\
25,000)\end{array}$ & $\begin{array}{l}6,290(1,400- \\
25,000)\end{array}$ & $\begin{array}{l}9,600(3,760- \\
19,870)\end{array}$ & 0.000 \\
\hline $\begin{array}{l}\% \text { WBC count decrease }(\%) * \\
\text { median (range) }\end{array}$ & $\begin{array}{l}57.1(11.7- \\
623.2)\end{array}$ & $\begin{array}{l}53.3(11.7- \\
623.2)\end{array}$ & $\begin{array}{l}83.4(35.3- \\
285.3)\end{array}$ & 0.000 \\
\hline Initial CRP (mg/dl), median (range) & $\begin{array}{l}3.45(0.02- \\
48.81)\end{array}$ & $\begin{array}{l}3.10(0.02- \\
48.81)\end{array}$ & $\begin{array}{l}6.87(0.06- \\
34.19)\end{array}$ & 0.001 \\
\hline $\begin{array}{l}\text { Post-treatment CRP (mg/dl), } \\
\text { median (range) }\end{array}$ & $\begin{array}{l}4.69(0.04- \\
48.95)\end{array}$ & $\begin{array}{l}4.00(0.04- \\
33.66)\end{array}$ & $\begin{array}{l}20.39(2.31- \\
48.95)\end{array}$ & 0.000 \\
\hline $\begin{array}{l}\% \text { CRP decrease }(\%)^{\star *} \text {, median } \\
\text { (range) }\end{array}$ & $\begin{array}{l}126.3(4.1- \\
71,300.0)\end{array}$ & $\begin{array}{l}114.6(4.1- \\
71,300.0)\end{array}$ & $\begin{array}{l}212.0(49.6- \\
12,750.0)\end{array}$ & 0.039 \\
\hline
\end{tabular}

Fecal stones

No

$184(54.6 \%)$

$177(57.3 \%)$

7 (25.0\%)

0.001

Yes

$153(45.4 \%)$

$132(42.7 \%)$

$21(75.0 \%)$

Abscess formation

No

$250(74.2 \%)$

$241(78.0 \%)$

$9(32.1 \%)$

0.000

Yes

$87(25.8 \%)$

$68(22.0 \%)$

$19(67.9 \%)$

Fecal stones + Abscess formation

No

Yes

Appendix diameter ( $\mathrm{mm})$, median (range)

$\begin{array}{llll}295(87.5 \%) & 281(90.9 \%) & 14(50.0 \%) & 0.000 \\ 42(12.5 \%) & 28(9.1 \%) & 14(50.0 \%) & \\ 11(5-30) & 11(5-30) & 14(8-20) & 0.000\end{array}$


*\% WBC count decrease $(\%)=$ Post WBC count $/$ Initial WBC count $\times 100$

$\star \star \%$ CRP decrease $(\%)=$ Post CRP level $/$ Initial CRP level $\times 100$

ASA-PS: American Society of Anesthesiologists Physical Status, WBC: white blood cell, CRP: C-reactive protein

Table 3. Results of multivariate analysis for variables that were significant in univariate analysis
Variable
Odds ratio $\quad 95 \% \mathrm{Cl}$
$\mathrm{p}$ value

\begin{tabular}{llll}
\hline Post-treatment CRP level $(\mathrm{mg} / \mathrm{dl})$ & 1.126 & $1.076-1.179$ & $\mathbf{0 . 0 0 0}$ \\
\hline Fecal stones + Abscess formation & 5.530 & $2.081-14.691$ & $\mathbf{0 . 0 0 1}$
\end{tabular}

95\% Cl: $95 \%$ confidence interval

Table 4. Patient characteristics, laboratory values, and imaging results in the recurrence and nonrecurrence groups 
Variable

Total $(n=195) \quad$ Recurrence

$(n=29)$

Non-recurrence

$(n=166)$

$\mathrm{p}$

value

Gender

\begin{tabular}{|c|c|c|c|c|}
\hline Male & 110 (56.4\%) & $14(48.3 \%)$ & 96 (57.8\%) & 0.338 \\
\hline Female & $85(43.6 \%)$ & $15(51.7 \%)$ & $70(42.2 \%)$ & \\
\hline Age (years), median (range) & $45.0(16-93)$ & $41.0(17-92)$ & $46.0(16-93)$ & 0.807 \\
\hline $\begin{array}{l}\text { Initial WBC }\left(/ \mathrm{mm}^{3}\right) \text {, median } \\
\text { (range) }\end{array}$ & $\begin{array}{l}12,710(1,380- \\
24,380)\end{array}$ & $\begin{array}{l}12,770(4,760- \\
23,610)\end{array}$ & $\begin{array}{l}12,695(1,380- \\
24,380)\end{array}$ & 0.849 \\
\hline $\begin{array}{l}\text { Post-treatment WBC }\left(/ \mathrm{mm}^{3}\right) \text {, } \\
\text { median (range) }\end{array}$ & $\begin{array}{l}6,110(1,400- \\
25,000)\end{array}$ & $\begin{array}{l}6,720(2,870- \\
14,500)\end{array}$ & $\begin{array}{l}6,100(1,400- \\
25,000)\end{array}$ & 0.664 \\
\hline $\begin{array}{l}\% \text { WBC decrease }(\%)^{\star} \text {, median } \\
\text { (range) }\end{array}$ & $\begin{array}{l}52.6(11.7- \\
623.2)\end{array}$ & $\begin{array}{l}53.2(26.4- \\
120.3)\end{array}$ & $\begin{array}{l}52.2(11.7- \\
623.2)\end{array}$ & 0.645 \\
\hline $\begin{array}{l}\text { Initial CRP (mg/dl), median } \\
\text { (range) }\end{array}$ & $\begin{array}{l}3.02(0.02- \\
42.06)\end{array}$ & $\begin{array}{l}0.95(0.02- \\
22.62)\end{array}$ & $\begin{array}{l}3.38(0.02- \\
42.06)\end{array}$ & 0.027 \\
\hline $\begin{array}{l}\text { Post-treatment CRP }(\mathrm{mg} / \mathrm{dl}) \text {, } \\
\text { median (range) }\end{array}$ & $\begin{array}{l}3.37(0.04- \\
31.05)\end{array}$ & $\begin{array}{l}2.21(0.04- \\
29.06)\end{array}$ & $\begin{array}{l}3.53(0.06- \\
31.05)\end{array}$ & 0.795 \\
\hline $\begin{array}{l}\text { CRP decreasing rate }(\%)^{\star *}, \\
\text { median (range) }\end{array}$ & $\begin{array}{l}113.8(4.1- \\
43,680.0)\end{array}$ & $\begin{array}{l}342.5(25.0- \\
16,745.0)\end{array}$ & $\begin{array}{l}99.0(4.1- \\
43,680.0)\end{array}$ & 0.036 \\
\hline
\end{tabular}

Fecal stones

$\begin{array}{lllll}\text { No } & 124(63.6 \%) & 19(65.5 \%) & 105(63.3 \%) & 0.815 \\ \text { Yes } & 71(36.4 \%) & 10(34.5 \%) & 61(36.7 \%) & \end{array}$

Abscess formation

\begin{tabular}{lllll} 
No & $169(86.7 \%)$ & $25(86.2 \%)$ & $144(86.7 \%)$ & 1.000 \\
\hline Yes & $26(13.3 \%)$ & $4(13.8 \%)$ & $22(13.3 \%)$ & \\
\hline
\end{tabular}

Fecal stones or Abscess

formation

$\begin{array}{lllll}\text { No } & 108(55.4 \%) & 18(62.1 \%) & 90(54.2 \%) & 0.433 \\ \text { Yes } & 87(44.6 \%) & 11(37.9 \%) & 76(45.8 \%) & \end{array}$

Fecal stones + Abscess

formation

\begin{tabular}{lllll}
\hline No & $186(95.4 \%)$ & $26(89.7 \%)$ & $160(96.4 \%)$ & 0.134 \\
\hline Yes & $9(4.6 \%)$ & $3(10.3 \%)$ & $6(3.6 \%)$ & \\
\hline Appendix diameter $(\mathrm{mm})$, & $11(5-25)$ & $10(7-18)$ & $11(5-25)$ & 0.515
\end{tabular}


median (range)

*\% WBC count decrease $(\%)=$ Post WBC count $/$ Initial WBC count $\times 100$

** \% CRP decrease $(\%)=$ Post CRP level $/$ Initial CRP level $\times 100$

ASA-PS: American Society of Anesthesiologists Physical Status

\section{Figures}

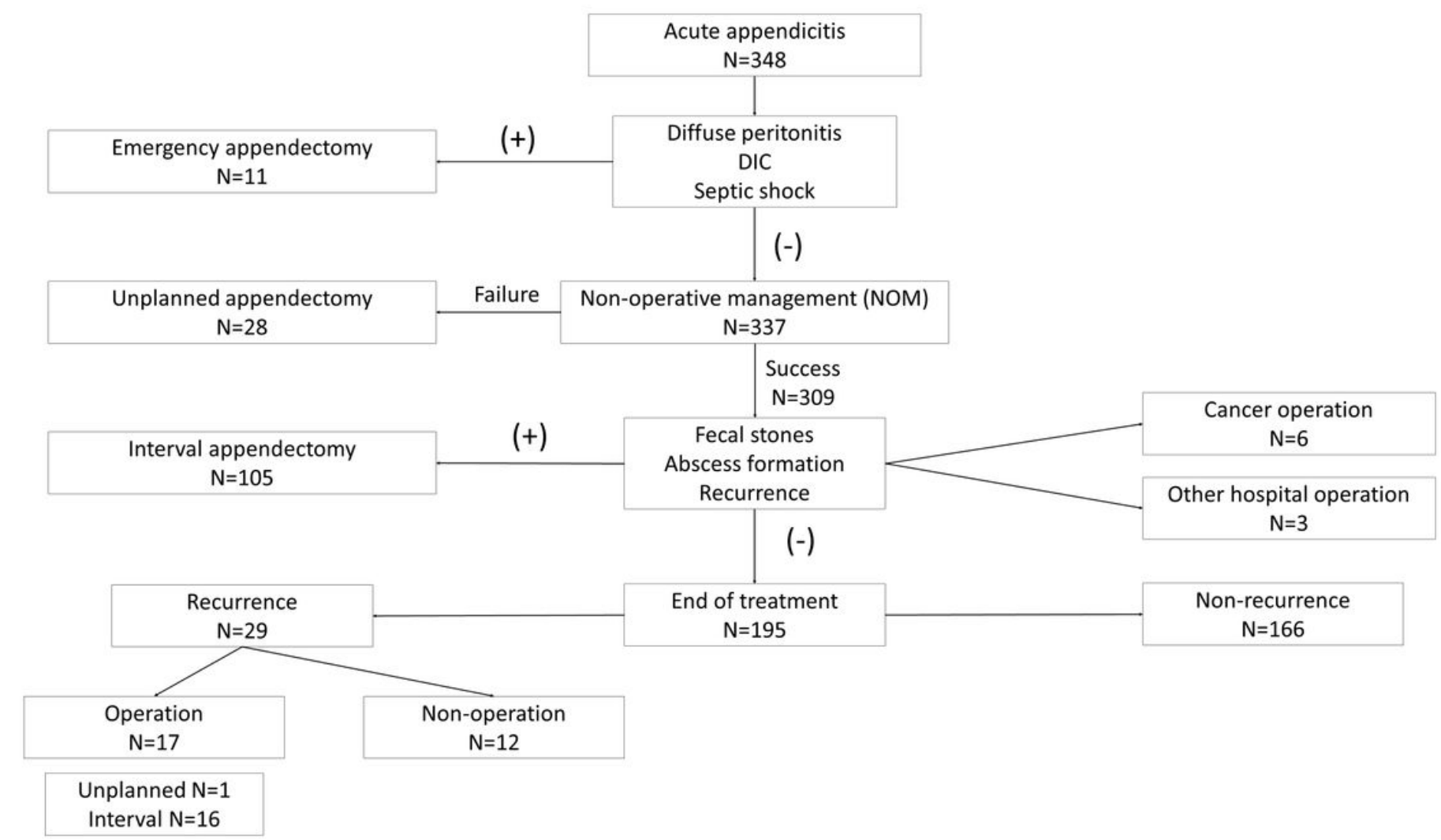

\section{Figure 1}

Flow diagram for the disposition of 348 patients who underwent treatment for appendicitis between April 2016 and October 2021. 


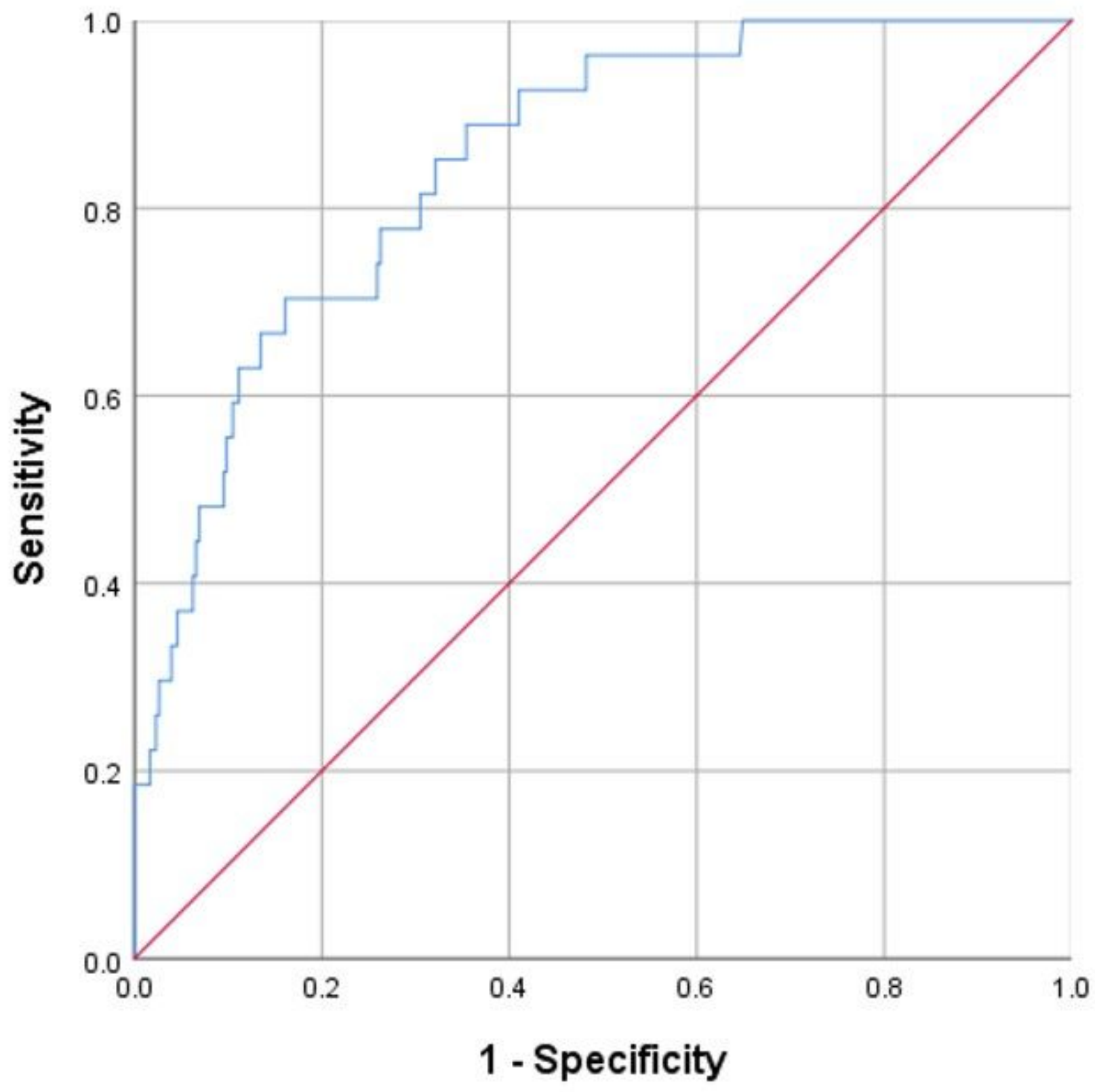

Figure 2

Receiver operating characteristic (ROC) curves of the relationship of the C-reactive protein (CRP) level with NOM failure.

\section{Supplementary Files}

This is a list of supplementary files associated with this preprint. Click to download.

- rawdata.xlsx 